\section{The end of the World}

\section{is not nigh}

Sir-My book The End of the World: the Science and Ethics of Human Extinction, reviewed by Freeman Dyson (Nature 380, 296; 1996), joined Richard Gott (Nature 363,315 ; 1993) in developing a point originated by Brandon Carter. People have some grounds for distrusting any theory that makes them very unusually early among all humans who will ever have been born. Taking account of this, they can justifiably re-estimate the risk that humankind will soon be extinct. They can become less confident in Dyson's suggestion (Reviews of Modern Physics 51, $246 ; 1979)$ that their descendants will continue onwards eternally.

Dyson calls it "typical" of the book to reason as follows: that if the number so far born is about a hundred billion then "our species has only a ten-per-cent chance of surviving as long as five hundred generations with our present size of population". In fact, however, the book follows Carter in arguing only for changes in the risk-estimates generated by examining various dangers. If Carter and I saw a gigantic asteroid rushing at us, or well funded plans for surviving asteroid impacts, then that would affect our probabilistic calculations. What Dyson calls typical bears scant resemblance to anything we have said. Further, we are innocent of the blunder he describes. We avoid assuming simultaneously (1) that, as he puts it, "we know nothing of our place in the history of our species", and (2) that we know we are placed "among the first hundred billion humans".

Consider the following story, told in the book. If fully funded, an experiment was sure to run as follows. Initially, three people would each receive an emerald. Several centuries later, emeralds would be given to 5,000 people. You yourself get an emerald. Imagine you are ignorant of your place in the population history of emerald-getters, but are certain the experiment was fully funded.

You should bet you are in the group of 5,000 . However, suppose you instead know you are in the group of three, much as we could know we are in the first hundred billion humans. This fortifies any suspicions you may have that the experiment was poorly funded, so that few emeralds will be distributed later. No blunder here! For you need not be assuming, first, that you know absolutely nothing of your place among emeraldgetters, so as to be able to ask in all seriousness whether you are in the group of three, and second, inconsistently, that you know you are in it. Instead, certain you are among the three, but unsure whether there will be 5,000 emerald-getters later, you can be rightly taking account of how likely you as an emerald-getter had been to find yourself among the three, against the background of competing theories about the funding.

Had the funding been so poor that only three emeralds would ever be distributed, then the likelihood was unity; with full funding, it was roughly 0.0006 . Taking account of such likelihoods is not claiming to be ignorant of what, in the very next breath, you say you know.

Take a simpler case. Two urns each contain three black balls. In one, there is nothing else; in the other, an additional 5,000 white. Having no idea of which is which, you choose an urn by tossing a coin. A ball is drawn, and it is black. You conclude that there is little chance that the urn is the one with the 5,000 white, for the likelihood of drawing a black ball from that urn had been so small. This reasoning does not involve declaring first that you are ignorant that a black ball has been drawn, and second that you know it. Asking what the likelihood would have been, on various hypotheses, that you would observe what you actually did observe, is fundamental to all science.

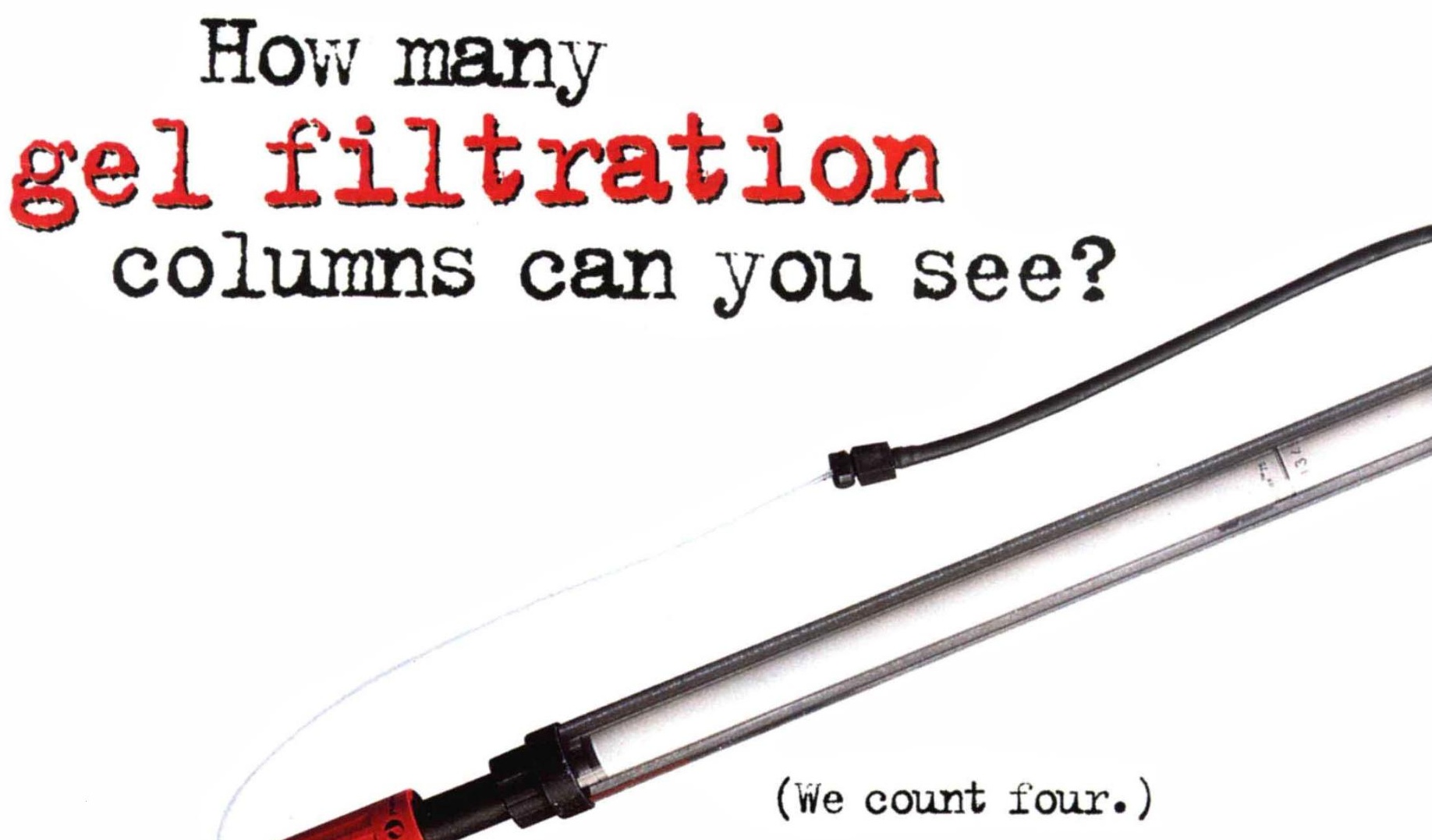


